\title{
Benign phyllodes fumour of the prostate: An extremely rare entity
}

\author{
Ozgu Aydogdu, MD; ${ }^{*}$ Yusuf Ziya Atesci, MD; ${ }^{*}$ Ayhan Karakose, MD; ${ }^{*}$ Eren Demirtas, $M D^{+}$
}

*Izmir University School of Medicine, Department of Urology, Izmir, Turkey; †'Mikro Pathology Laboratory, Izmir, Turkey

Cite as: Can Urol Assoc J 2014;8(7-8):e548-51. http://dx.doi.org/10.5489/cuaj.2030 Published online August 11, 2014.

\section{Abstract}

Benign phyllodes tumour (BPT) of the prostate is a very rare neoplasm. It is composed of hyperplastic and neoplastic glandular stromal proliferation. Patients with BPT of the prostate generally present with lower urinary tract symptoms and hematuria. BPT of the prostate can potentially cause recurrent obstructive symptoms. Complete transurethral resection (TUR) and close postoperative follow-up is recommended. A 59-year-old man presented with dysuria and obstructive urinary symptoms. Flexible cystoscopy revealed prostatic hyperplasia and a polypoidal lesion originating from the right lateral lobe of the prostate. Magnetic resonance imaging revealed a $3 \times 2.5-\mathrm{cm}$ mass lesion in the right lateral lobe of the prostate. TUR of the prostate was performed and the pathological examination revealed benign prostatic hyperplasia and benign phyllodes tumour of the prostate.

\section{Introduction}

Benign phyllodes tumour (BPT) of the prostate is extremely rare. ${ }^{1}$ Phyllodes tumours, namely epithelial-stromal tumours of the prostate, were first reported in 1960 by Cox and colleagues. ${ }^{2}$ Men with BPT of the prostate mostly present with obstructive urinary symptoms and microscopic or macroscopic hematuria. ${ }^{3,4}$ BPT of the prostate can potentially recur and cause repetitive obstructive urinary symptoms. ${ }^{3}$ In some cases dedifferentiation, infiltrative growth and extraprostatic invasion can possibly be observed. ${ }^{1}$

Histological features are similar to phyllodes tumours of the mammary gland. ${ }^{1}$ Cystically dilated ducts with leaf-like stromal projections are typical for phyllodes tumors of both mammary and prostate glands. ${ }^{4}$ An individualized approach to complete resection of the prostate and BPT is required. ${ }^{1}$ All patients who undergo transurethral resection of the prostate (TURP) as initial surgical treatment should be closely followed for possible recurrence and extraprostatic spread. We report the case of a 59-year-old man with extremely rare benign tumour of the prostate, which was incidentally recognized in flexible cystoscopy.

\section{Case report}

A 59-year-old man presented to the urology outpatient clinic with lower urinary tract symptoms and dysuria. His medical history revealed no additional diseases and/or previous surgical interventions. His total prostate-specific antigen (PSA) was $3.1 \mathrm{ng} / \mathrm{mL}$ and the digital rectal examination revealed an enlarged benign-feeling prostate. Urine analysis was normal and suprapubic ultrasound scan revealed a prostatic volume of $65 \mathrm{~mL}$. Uroflowmetry was performed and the maximum urinary flow rate (Qmax) and average urinary flow rate (Qave) were $7 \mathrm{~mL} / \mathrm{s}$ and $5 \mathrm{~mL} / \mathrm{s}$, respectively. Flexible cystoscopy revealed prostatic hyperplasia and a polypoidal lesion originating from the right lateral lobe of the prostate in the prostatic urethra (Fig. 1). The abdominal-pelvic magnetic resonance imaging (MRI) revealed a $3 \times 2.5-\mathrm{cm}$ mass lesion in the right lateral lobe of the prostate, without metastatic lesions or lymph node involvement (Fig. 2). The proctosigmoidoscopy was normal. The patient underwent a TURP and the postoperative period was uneventful. The urethral catheter was removed on postoperative day 4 and the patient was discharged on the same day after he voided spontaneously. Pathological examination was reported as benign prostate hyperplasia (BPH) and BPT of the prostate (Fig. 3).

Microscopic examination showed a polypoidal mass, which was formed by cystic and variously shaped glands and stroma at $\times X 50$ magnification (Fig. 3, part A). The tumour, including thin and long branching glands and cellular stroma, was observed at $\times 100$ magnification (Fig. 3, part B). The $\times 200$ magnification revealed benign prostatic glands and cellular spindle-shaped stromal components (Fig. 3, part C). Benign prostatic glands, atypia and oval, spindle- 


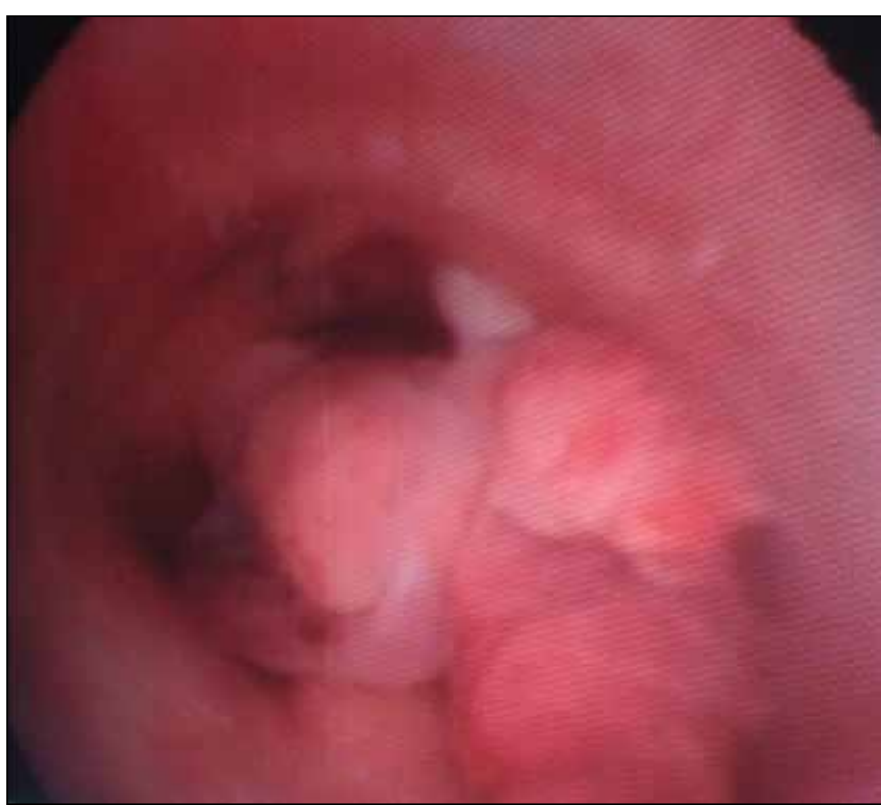

Fig. 1. Flexible cystoscopy revealed prostatic hyperplasia and a polypoidal lesion originating from the right lateral lobe of the prostate in the prostatic urethra.

shaped stromal cells, with no mitotic activity, were observed at $\times 400$ magnification during the microscopic examination (Fig. 3, part D).

Periodical close follow-up was planned since BPT of the prostate has malignant potential and a high recurrence rate. The patient was informed of the possible radical surgical intervention in terms of any progression at an early stage during follow-up.
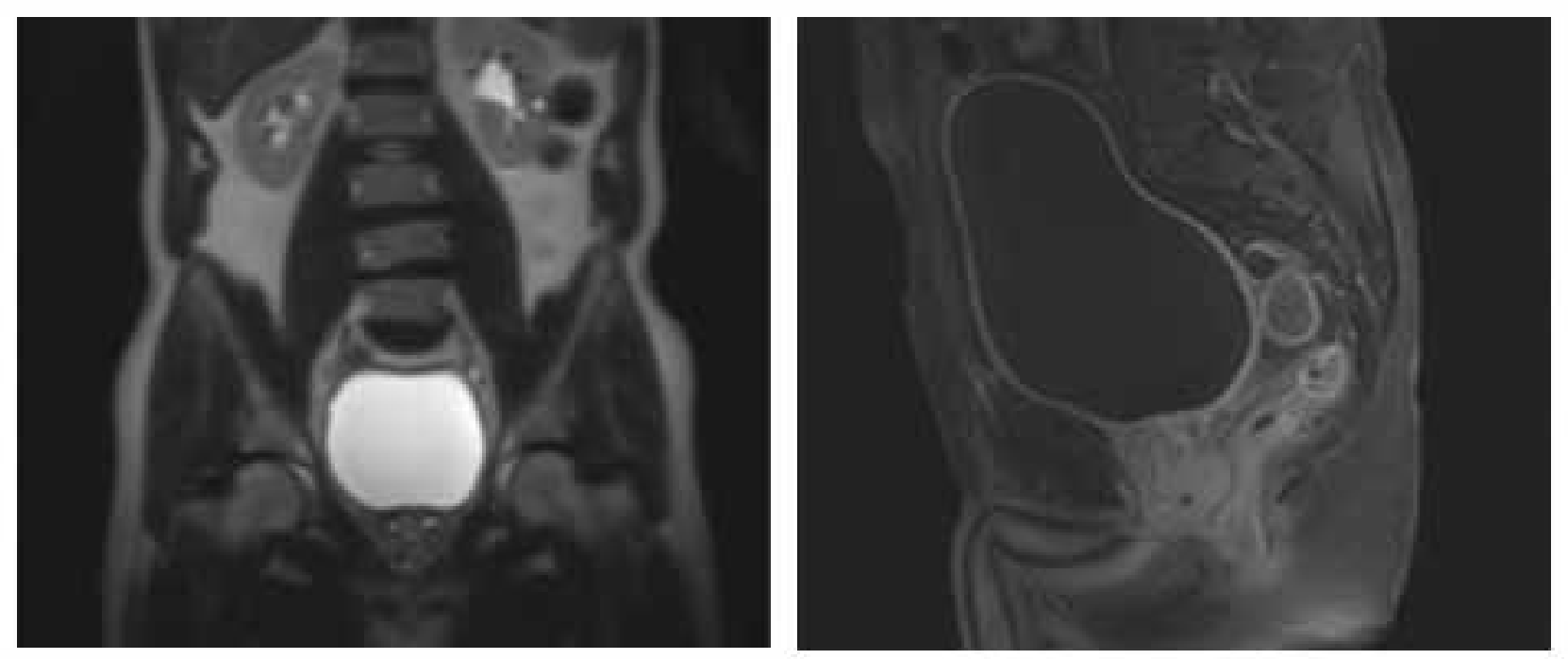

Fig. 2. Abdominal-pelvic magnetic resonance imaging revealed a $3 \times 2.5-\mathrm{cm}$ mass lesion in the right lateral lobe of the prostate without any metastatic lesions or lymph node involvement.
Phyllodes tumour of the prostate is an extremely rare prostatic neoplasm. There is a great variability in the histological appearance and clinical behaviour of this tumour. ${ }^{1}$ Less than 90 cases were reported to date. BPT of the prostate without mitotic activity, as was the case in our patient, is even more rare. In the mammary gland, the presence of high cellularity and mitotic activity correlates with tumours of malignant and metastasizing potential. ${ }^{4,5}$

Age at presentation ranges from 22 to 86 years and most patients are over $50 .{ }^{1}$ Patients with BPT of the prostate generally present with dysuria, hematuria, obstructive urinary symptoms and urinary retention mimicking benign prostatic obstruction. ${ }^{1,4}$ Some of the patients may present with a palpable abdominal mass. ${ }^{1,3}$ Our patient presented with obstructive urinary symptoms and dysuria without hematuria and/or palpable abdominal mass. On MRI the phyllodes tumour may appear lobulated and partially cystic. ${ }^{1}$ MRI findings of our patient revealed a $3 \times 2.5-\mathrm{cm}$ solid lesion in the right lateral lobe of the prostate without a cystic component (Fig. 2).

Diagnosis with needle biopsy is difficult and most cases are diagnosed initially after transurethral resection. ${ }^{1,6}$ In our patient, flexible cystoscopy revealed a polypoidal lesion originating from the right lateral lobe of the prostate in the prostatic urethra and we decided to perform transurethral resection for pathological diagnosis since the transrectal biopsy might not demonstrate distinctive histological features. Phyllodes tumours of the prostate include stromal and epithelial components, which are arranged to form cysts lined by hyperplastic epithelium. ${ }^{1}$ Basal cell and secretory layers of the epithelium may show metaplastic and prolifera-

\section{Discussion}



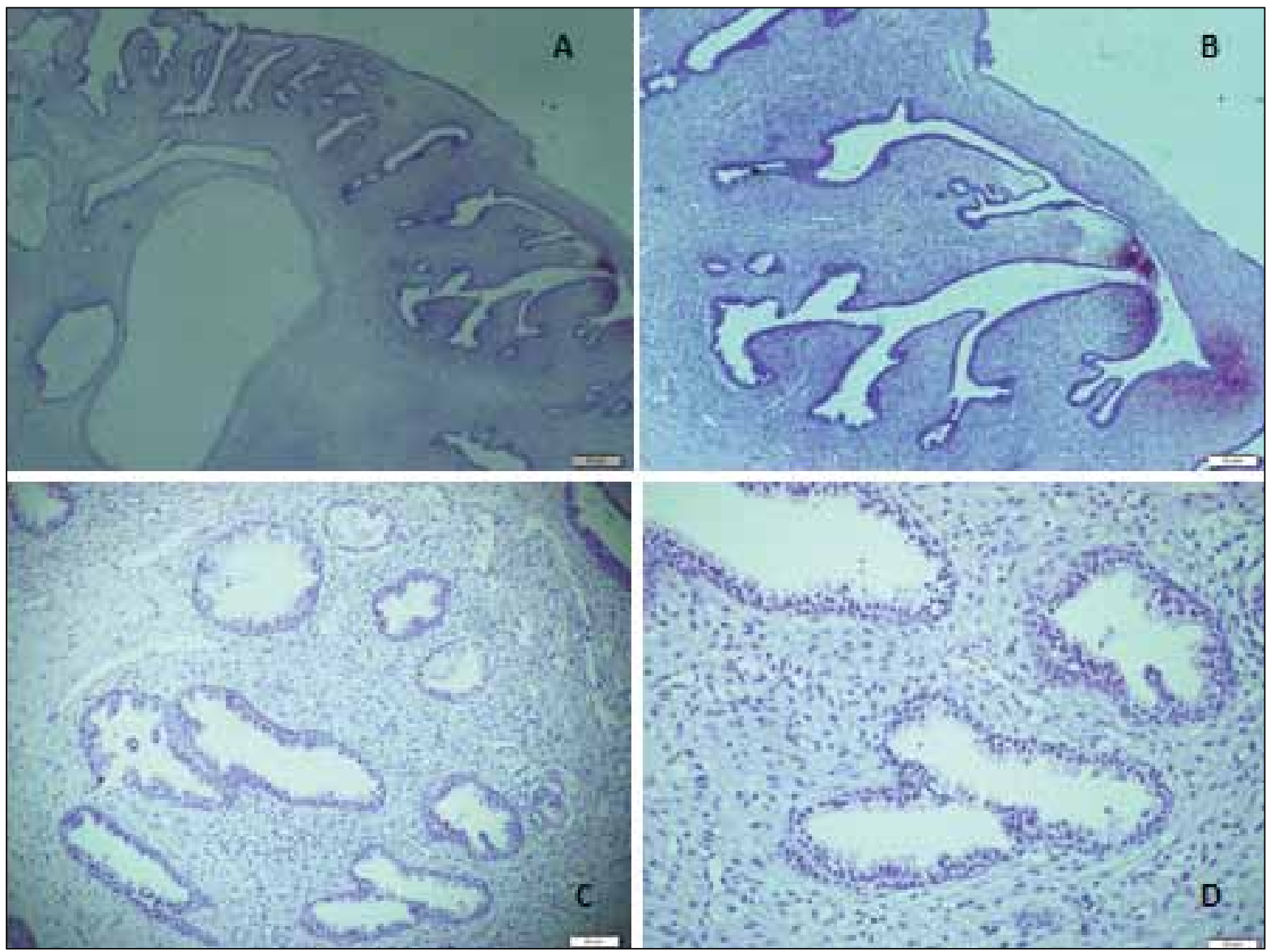

Fig. 3. A: Microscopic examination showed a polypoidal mass which is formed by some cystic and variously shaped glands and stroma at X50 magnification. B: Tumour, including thin and long branching glands, and cellular stroma was observed at $\times 100$ magnification. C: The $\times 200$ magnification revealed benign prostatic glands and cellular spindle shaped stromal component. D: Benign prostatic glands, atypia and oval, spindle shaped stromal cells, which do not have mitotic activity, were observed in $\times 400$ magnification in microscopic examination.

tive changes, including basal cell hyperplasia or squamous metaplasia. ${ }^{1,7}$ There is a wide variability in terms of cellularity, atypia, necrosis and mitotic activity. These histological features guide the pathologist to assign tumour grade. ${ }^{1}$ No mitotic activity was observed in the recent case. Although the histogenesis of phyllodes tumour of the prostate remains unclear, various proliferation indexes, including $\mathrm{Ki}-67$ and proliferative nuclear antigens (PCNA) or p53 expression, may guide clinicians in their immunohistochemical evaluation. $^{4}$

Complete tumour resection may provide the best chance for cure. ${ }^{1,3}$ However, the recurrence rate after transurethral resection of phyllodes tumour of the prostate was between $50 \%$ and $100 \%{ }^{1,6}$ Phyllodes tumour of the prostate has malignant potential and multiple recurrences are frequently associated with aggressive tumour behavior and sarcomatous transformation. ${ }^{1,3,4}$ Therefore, close follow-up with digital rectal examination, transrectal ultrasound scan, MRI and cystoscopy is necessary. Benign phyllodes tumour of the prostate, as seen in our case, has possible local proliferative activity without metastatic potential and multiple transurethral resections may be required in some patients. ${ }^{4}$ In a previous study the authors reported a locally recurring case following resection of BPT of the prostate. ${ }^{8}$ Radical prostatectomy was reported as one of the surgical treatment options in patients with recurrent obstructive symptoms. In a recent study, the authors reported on a 47-year-old man with elevated serum PSA of $60.76 \mathrm{ng} / \mathrm{mL} .{ }^{9}$ Needle biopsy revealed atypical stromal cells without evidence of malignancy. Radical prostatectomy was performed and the pathology was reported as phyllodes tumour of the prostate. In addition, endocrine therapies, including anti-androgen agents, can be used in the treatment of phyllodes tumors of the prostate. ${ }^{1,4}$ Previous studies showed significantly increased expression of epidermal growth factor receptor (eGFR) and androgen receptor in both epithelial and stromal components of phyl- 
lodes tumour of the prostate. ${ }^{1,10}$ Targeted therapies, including anti-eGFR and anti-androgen agents, may be used in patients with phyllodes tumour of the prostate.

\section{Conclusion}

Phyllodes tumour of the prostate is an extremely rare pathology. The patient reported here represents a rarer case with BPT of the prostate without mitotic activity. Since BPT of the prostate is potentially aggressive and the local recurrence rate is relatively high, complete tumour resection provides the best chance for cure. Close periodical follow-up is essential, as progression requiring more aggressive surgical intervention can be observed.

Competing interests: Dr. Aydogdu, Dr. Atesci, Dr. Karakose and Dr. Demirtas all declare no competing financial or personal interests.

This paper has been peer-reviewed.

\section{References}

1. Bannawsky A, Probst A, Dunker $\mathrm{H}$, et al. Rare and challenging tumor entity: Phhyllodes tumor of the prostate. J Oncol 2009;241270. http://dx.doi.org/10.1155/2009/241270

2. Cox R, Dawson IM. A curious prostate tumor: probably a true mixed tumor (cystadeno-leiomyofibroma). Br J Urol 1960;32:306-11. http://dx.doi.org/10.1111/j.1464-410X.1960.tb11551.x

3. Aguilar B, Villalobos M, Stomayor M. Phyllodes tumor of the prostate. Urol 2009;73:272. http://dx.doi. org/10.1016/i.urology.2008.08.466

4. Shiraishi K, Mohri J, Eguchi S, et al. Phyllodes tumor of the prostate: Recurrent obstructive symptom and stromal proliferative activity. Int J Urol 2004;11:801-4. http://dx.doi.org/10.1111/j.14422042.2004.00875.x

5. Terrier $P$, Terrier-Lacombe MJ, Mouriesse $H$, et al. Primary breast sarcoma: A review of 33 cases with immunohistochemistry and prognostic factors. Breast Cancer Res Treat 1989;13 39-48. hittp://dx.doi. org/10.1007/BF01806549

6. Bostwick DG, Hossain D, Qian J, et al. Phyllodes tumor of the prostate: Long-term followup study of 23 cases. J Urol 2004;172:894-9. http://dx.doi.org/10.1097/01.ju.0000134580.71261.57

7. Gaudin PB, Rosai J, Epstein JI. Sarcomas and related proliferative lesions of specialized prostatic stroma: A clinicopathologic study of 22 cases. Am J Surg Pathol 1998;22:148-62. http://dx.doi. org/10.1097/00000478-199802000-00002

8. Fujita K, Matsushima H, Munakata A. Phyllodes type of atypical prostatic hyperplasia. Int I Urol 1996;3:158-60. htrp://dx.doi.org/10.1111/i.1442-2042.1996.tb00504.x

9. Fujii T, Shimada K, Tanaka N, et al. Phyllodes tumor of the prostate. Pathol Int 2012;62:204-8. http:// dx.doi.org/10.1111/i.1440-1827.2012.02796.x

10. Wang $X$, Jones TD, Zhang $S$, et al. Amplifications of EGFR gene and protein expression of EGFR, Her-2/ neu, c-kit, and androgen receptor in phyllodes tumor of the prostate. Mod Pathol 2007;20:175-82. http://dx.doi.org/10.1038/modpathol.3800724

Correspondence: Dr. Ozgu Aydogdu, Izmir University School of Medicine, Department of Urology, Yeni Girne blv. 1825 sk. No: 12 Karsiyaka, Izmir, Turkey; 0zgucan@yahoo.com 